\title{
Age-Related Changes in Auditory Nogo-N200 Latency in Medication-Naïe Children and Adolescents with Attention-Deficit/Hyperactivity Disorder
}

\author{
Yeon Jung Lee ${ }^{\bowtie}$, Mi Young Jeong ${ }^{2}$, Seoyoung Park², Jung Ho Kim³, Ji-Sun Kim4, and Sung-II Woo ${ }^{1}$ \\ 'Department of Psychiatry, Seoul Hospital, College of Medicine, Soonchunhyang University, Seoul, Republic of Korea \\ 2Department of Medical Sciences, Graduate School of Soonchunhyang University, Asan, Republic of Korea \\ ${ }^{3}$ Department of Nursing, Masan University, Changwon, Republic of Korea \\ ${ }^{4}$ Department of Psychiatry, Cheonan Hospital, College of Medicine, Soonchunhyang University, Cheonan, Republic of Korea
}

\begin{abstract}
Objective Event-related potential (ERP) changes with brain development in healthy children and adolescents. However, few studies have focused on age-related changes in the N200 and P300 components among individuals with attention-deficit/hyperactivity disorder (ADHD). Therefore, this study aimed to assess age-related differences in the auditory nogo-N200 components in individuals with ADHD. Methods We enrolled 46 participants with auditory nogo-N200 and nogo-P300 components. We assessed ADHD symptoms using the Advanced Test of Attention (ATA) and Korean ADHD Rating Scale-IV (K-ARS-IV). Moreover, we assessed emotional and behavioral problems using the Korean Child Behavior Checklist (K-CBCL). Further, we measured auditory ERPs.

Results There were no differences with respect to sex or ATA, K-ARS-IV, and K-CBCL scores between the groups. With a 1-year increase in age, the nogo-N200 latency at Fz and Cz decreased by $6.08 \mathrm{~ms}$ and $4.88 \mathrm{~ms}$, respectively; this result was statistically significant in multivariable linear regression adjusted by sex and dominant hand.

Conclusion Our findings revealed age-related changes in nogo-N200 latency at the Fz and Cz electrodes in individuals with ADHD. Future studies should perform comparisons with healthy controls to determine whether auditory nogo-N200 can be used to evaluate the developmental level in individuals with ADHD.

Psychiatry Investig 2020;17(7):702-709
\end{abstract}

Key Words Attention-deficit/hyperactivity disorder, Evoked potentials, Electroencephalography, Child, Adolescent.

\section{INTRODUCTION}

Attention-deficit/hyperactivity disorder (ADHD) is the most commonly diagnosed neurodevelopmental disorder with a prevalence of 3-7\% among school-aged children. ${ }^{1,2}$ The essential diagnostic criteria of ADHD include developmentally inappropriate levels of impulsivity, hyperactivity, and inattention. ${ }^{3}$ These symptoms persist into adolescence and adulthood in $70-80 \%$ and $50 \%$ of all cases, respectively. ${ }^{3,4}$ ADHD affects almost every area of daily functioning and causes academic, peer

\footnotetext{
Received: March 3, 2020 Revised: April 22, 2020

Accepted: May 14, 2020

$\triangle$ Correspondence: Yeon Jung Lee, MD, $\mathrm{PhD}$

Department of Psychiatry, Seoul Hospital, College of Medicine, Soonchunhyang University, 59 Daesagwan-ro, Yongsan-gu, Seoul 04401, Republic of Korea Tel: +82-2-709-9081, Fax: +82-2-792-5976, E-mail: leeyj1203@schmc.ac.kr

(c) This is an Open Access article distributed under the terms of the Creative Commons Attribution Non-Commercial License (https://creativecommons.org/licenses/bync/4.0) which permits unrestricted non-commercial use, distribution, and reproduction in any medium, provided the original work is properly cited.
}

relationship, and socioeconomic problems. ${ }^{3,4}$

The precise etiology of ADHD is unknown; however, the most prominent hypotheses suggest that it involves changes in brain maturation. It is unclear whether ADHD is associated with delayed brain maturation ${ }^{5,6}$ or with abnormal brain maturation. ${ }^{7,8}$ Structural brain imaging studies mainly support the delayed brain maturation hypothesis with two longitudinal studies demonstrating that children with ADHD present the normal developmental cortical thickening pattern. ${ }^{6,9}$ Shaw et al. ${ }^{6}$ reported that cortical thickness in healthy children and youth with ADHD, which peaked during early childhood, occurred later in the frontotemporal cortex in individuals with ADHD prior to the cortical thinning phase. Further, the thinning velocity was consistently slower in youth with ADHD. ${ }^{9}$ The longest delays (approximately 2-3 years) have been observed in the prefrontal cortex, which is known to be associated with the pathophysiology of ADHD.,

Event-related potentials (ERPs) have been extensively used 
in developmental research on human brain maturation associated with perceptual and cognitive development. ${ }^{10-12}$ ERPs allow non-invasive assessment with a high temporal resolution of subtle cognitive activity, which makes them useful in the evaluation of cognitive function. ${ }^{13}$ Several studies ${ }^{12,14,15}$ have reported that a decrease in the P300 latency from childhood to adolescence. P300 latency, which is sensitive to neuronal changes with development and aging, ${ }^{15,16}$ increases at a rate of 1-2 ms/ year ${ }^{17}$ and can provide useful information regarding cognitive function and aging. P300 latency is inversely related to age due to brain maturation processes, including myelination and cognitive development in children and adolescents. ${ }^{13,14}$ Compared with P300, there have been fewer studies on N200. However, similar to P300 latency, N200 latency decreases with age in individuals aged below 30 years. ${ }^{14,18}$ Deficits in inhibitory control, which is among the core symptoms in children with ADHD, can be assessed with a high temporal resolution by recording P300 and N200 using go-nogo tasks involving tap response inhibition. ${ }^{19}$ Compared with go trials, nogo trials have been shown to have greater amplitudes for N200 in the frontal area and P300 in the frontocentral area. ${ }^{20,21}$ The nogo P300 component is reduced in response to stop signals in children with $\mathrm{ADHD},{ }^{22}$ which is associated with late-stage monitoring of the outcome of inhibitory processes. ${ }^{23}$ Moreover, nogo N200 components have been reported to be abnormally reduced in children with ADHD than those in normal children, ${ }^{24}$ which is associated with early stage of inhibitory control that reflects a "red flag" signal generated in the prefrontal cortex to trigger inhibitory processes. ${ }^{25}$ Previous studies have confirmed changes in N200 and P300 components with brain development and that they may be used to evaluate altered inhibitory control, which is an ADHD symptom, through go-nogo tasks. However, there have been no studies using N200 and P300 to examine age-related changes in children and adolescents with ADHD. Accordingly, we aimed to identify age-related differences in the N200 and P300 components, hypothesizing that N200 and P300 amplitudes are lowered and their latencies shortened with age.

\section{METHODS}

\section{Participants}

This cross-sectional study was conducted between January 2018 and June 2019 at the psychiatry department of a university hospital in Seoul. An experienced pediatric psychiatrist conducted clinical interviews and assessments on children and adolescents with their parents. The inclusion criteria were: 1 ) aged between 6 and 18 years and 2) a main diagnosis of ADHD according to the criteria provided by the Diagnostic and Statistical Manual of Mental Disorders, Fifth Edition (DSM-5). ${ }^{3}$ The exclusion criteria were 1) brain injury, 2) other mental disor- ders except ADHD in the main diagnosis, and 3) failure to provide consent by either the children/adolescents or their parents. Of the 56 children and adolescents who participated in this study, 10 individuals whose N200 and P300 components were difficult to analyze due to excessive movements were excluded. Consequently, 46 children and adolescents were included as the study cohort. The majority of participants had no history of taking psychiatric medication and those taking medication underwent a medication washout for at least one week before participating in the study. This is because methylphenidate had been shown to normalize lower P300 amplitudes in children and adolescents with ADHD. ${ }^{26,27}$ Forty-four participants were right-hand dominant, and two participants were left-hand dominant. All participants and their parents provided written informed consent following the Declaration of Helsinki using a form reviewed and approved by the Institutional Review Board of Soonchunhyang University Seoul Hospital (No. 2017-08-003).

\section{Instruments}

\section{Korean ADHD Rating Scale-IV}

DuPaul et al. ${ }^{28}$ developed the ADHD Rating Scale (ARS-IV) as a measure of hyperactivity and problematic behaviors in children and adolescents. This scale is composed of 18 items following the ADHD diagnostic criteria of the DSM-IV. Each item is rated on a four-point Likert scale based on the frequency of the child's problematic behavior: "never or rarely" is scored 0 , "sometimes" is scored 1, "often" is scored 2, and "very often" is scored 3. A score of $\geq 2$ is considered abnormal relative to the developmental stage of healthy children and adolescents. The tool is arranged such that the total score of odd-numbered items measures inattention while that of even-numbered items measures hyperactivity-impulsivity. In the Korean ARS-IV (K-ARSIV), higher scores on the inattention and hyperactivity-impulsivity subscales indicate greater severity of ADHD symptoms. In the K-ARS standardized by Jang et al., ${ }^{29}$ Cronbach's alpha was $0.74-1$ while the validity was $0.06-0.59$, indicating a high correlation.

\section{Advanced Test of Attention}

The Advanced Test of Attention (ATA) is a computerized continuous performance test ${ }^{30}$ for the identification of inattention and impulsivity in children and adolescents. This test, which includes two modules (visual and auditory), investigates omission errors, commission errors, mean response time, and standard deviation of response time. In this study, we used the ADHD Index of the auditory test, whereby a score of $\geq 115$ indicates abnormal development. The ATA has been standardized for use in South Korean children and adolescents. ${ }^{30}$ The 
accuracy of discrimination between children with normal development and children with ADHD is $96.7 \%$ and Cronbach's alpha is 0.87 .

\section{Korean Child Behavior Checklist}

The Child Behavior Checklist (CBCL) is a parent-reported tool that examines emotional and behavioral problems in children and adolescents aged between 6 and 18 years. ${ }^{31}$ The instrument consists of items for problematic behavior symptoms and social competence.

The CBCL assesses internalizing, externalizing, and total problems. The subareas examined include social withdrawal, anxiety and depression, somatic complaints, destructive behavior, social problems, thought problems, attention problems, rule-breaking behavior, and aggressive behavior. It is comprised of 113 questions on a 3-point Likert scale. The Korean version (K-CBCL) has been standardized by Oh and Lee. ${ }^{32}$ In this study, we used a T-score of internalizing problems, externalizing problems, and total problems, with a T-score of $\geq 65$ indicating abnormal development. Cronbach's alpha of the K-CBCL is $0.62-$ $0.86^{32}$

\section{EEG acquisition and analysis}

The participants were seated on a comfortable chair in a soundattenuated space. The EEG was recorded using a NeuroScan SynAmps amplifier (Compumedics USA, El Paso, TX, USA) and $\mathrm{Ag}-\mathrm{AgCl}$ electrodes based on a modified 10-20 placement scheme. The ground electrode was placed on the forehead and reference electrodes at the mastoids. The inter-electrode impedance was maintained at $<10 \mathrm{k} \Omega$. Averaging of the ERP waves and related procedures was performed using the NeuroScan version 4.3 software package (Compumedics, USA). All EEG data were recorded using a $0.1-100 \mathrm{~Hz}$ band-pass filter at a sampling rate of $1,000 \mathrm{~Hz}$.

The recorded EEG data were preprocessed using CURRY 8. Gross movement artifacts were removed from the recorded data by visual inspection. Moreover, eye blink artifacts were removed using established mathematical procedures. ${ }^{33}$ Trials were rejected if they presented important physiological artifacts (amplitude exceeding $\pm 75 \mu \mathrm{V}$ ) at any cortical electrode site.

\section{Nogo condition}

The E-Prime (Psychology Software Tools, Pittsburgh, PA, USA) was used to conduct stimulus presentation and data synchronization with the EEG. A stimulation protocol used the auditory oddball paradigm. Infrequent target tones of $1,500 \mathrm{~Hz}$ were randomly shown with frequent standard tones of $1,000 \mathrm{~Hz}$. The probabilities of standard and target tones were $85 \%$ and $15 \%$, respectively. A total of 400 auditory stimuli were presented. The tone duration was $100 \mathrm{~ms}$ with rise-fall times of $10 \mathrm{~ms}$ and an inter-stimulus interval of 1,500 ms. The experimental block consisted of 400 stimuli that followed a practice block of 20 stimuli. These auditory stimuli were delivered via MDRXB950N1 headphones (Sony, Tokyo, Japan) at $85 \mathrm{~dB}$ SPL. The participants were asked to promptly press a button in response to standard tones (go condition) and to promptly stop a button in response to target tones (nogo condition). We analyzed N200 and P300 components within the nogo condition because the most common error type is the commission error, ensuing from failure to inhibit the response to the nogo stimulus. ${ }^{3}$ In the nogo condition, N200 (most negative peak between 150 and 350 ms after stimulus onset) and P300 (most positive peak between 200 and $450 \mathrm{~ms}$ after stimulus onset) were investigated at the $\mathrm{Fz}, \mathrm{Cz}$, and $\mathrm{Pz}$ electrodes.

\section{Statistical analyses}

Statistical analyses were conducted using $\mathrm{R}$ version 3.5.0 for Windows and Rex (Version 3.0.3, RexSoft Inc., Seoul, Republic of Korea). First, participants were divided into children with ADHD (6-11 years old) and adolescents with ADHD (12-18 years old). These age classifications were defined according to general guidelines. ${ }^{34}$ Data are indicated as mean \pm standard deviation (SD). The sex difference between the two groups was confirmed using the Fisher's exact test, and the differences in ATA, K-ARS-IV, and K-CBCL (internalizing, externalizing, and total) scores were confirmed using the Mann-Whitney U test. Second, we calculated the latency of N200 and the amplitude of P300 at the Fz, Cz, and Pz electrodes between the groups using the Mann-Whitney U test. Third, we calculated Spearman's correlation coefficient $(\rho)$ for the relationships between age change and ERPs (latency of N200 and amplitude of P300) at the $\mathrm{Fz}, \mathrm{Cz}$, and $\mathrm{Pz}$ electrodes. Subsequently, Bonferroni correction was performed. Fourth, multivariable regression analysis was used to calculate $95 \%$ confidence intervals (CIs) to assess the association of age with N200 latency at the Fz and $\mathrm{Cz}$ electrodes. Since sex ${ }^{15}$ and the dominant hand ${ }^{35}$ have been shown to significantly influence P300/N200 components, they were adjusted as covariates in the multivariable regression analysis. A p-value of $<0.05$ was considered statistically significant.

\section{RESULTS}

\section{Demographic and psychological characteristics of the participants}

Table 1 depicts comparisons of demographic and psychological characteristics between children and adolescents. The mean age of the two groups was 8.14 years (SD 1.21, range $6-10)$ and 14.08 years (SD 1.89, range $12-17$ ), respectively $(\mathrm{p}<$ $0.001)$. There were no significant differences with respect to $\operatorname{sex}(\mathrm{p}=0.13)$, ATA index $(\mathrm{p}=0.52), \mathrm{K}$-ARS score $(\mathrm{p}=0.25)$, and 
Table 1. Comparison of demographic and psychological characteristics between children and adolescents with ADHD

\begin{tabular}{|c|c|c|c|c|c|}
\hline & \multicolumn{2}{|c|}{ Children $(\mathrm{N}=22)$} & \multicolumn{2}{|c|}{ Adolescents (N=24) } & \multirow{2}{*}{$\mathrm{p}$} \\
\hline & $\mathrm{N}$ & $\%$ & $\mathrm{~N}$ & $\%$ & \\
\hline Sex & & & & & 0.13 \\
\hline Boys & 15 & 68.18 & 11 & 45.83 & \\
\hline \multirow[t]{2}{*}{ Girls } & 7 & 31.82 & 13 & 54.17 & \\
\hline & Mean & SD & Mean & SD & $\mathrm{p}$ \\
\hline Age & 8.14 & 1.21 & 14.08 & 1.89 & $<0.001^{* * *}$ \\
\hline Nogo trials & 52.54 & 8.69 & 48.18 & 10.90 & 0.10 \\
\hline Nogo false alarm rate (\%) & 27.72 & 15.59 & 20.36 & 10 & 0.10 \\
\hline ATA index & 117.36 & 21.87 & 115.5 & 19.54 & 0.52 \\
\hline K-ARS-IV & 23.05 & 13.08 & 19.38 & 8.36 & 0.25 \\
\hline \multicolumn{6}{|l|}{$\mathrm{K}-\mathrm{CBCL}$} \\
\hline Total score & 66.55 & 11.56 & 65.79 & 12.98 & 0.82 \\
\hline Internalizing & 63.09 & 11.50 & 64.50 & 11.67 & 0.47 \\
\hline Externalizing & 65.95 & 12.82 & 63.42 & 12.64 & 0.82 \\
\hline
\end{tabular}

The p-value for sex was calculated by Fisher's exact test. p-values for age, ATA index, K-ARS-IV, and K-CBCL were calculated with the MannWhitney U test. ${ }^{* * *} \mathrm{p}<0.001$. SD: standard deviation, ATA: advanced test of attention, K-ARS-IV: Korean-attention-deficit/hyperactivity disorder rating scale-IV, K-CBCL: Korean-Child Behavior Checklist

K-CBCL score (total, internalizing, and externalizing: $\mathrm{p}=0.82$, $\mathrm{p}=0.47, \mathrm{p}=0.82$, respectively) between the groups. No differences were observed in the nogo trial counts and nogo false alarm rates between the two groups ( $\mathrm{p}=0.10, \mathrm{p}=0.10$, respectively).

\section{EEG data}

Figure $1 \mathrm{~A}$ and $\mathrm{B}$ show the grand averages of auditory evoked potentials at the $\mathrm{Fz}$ and $\mathrm{Cz}$ electrodes, respectively, in both groups. Figure 1C illustrates the scalp topographies of nogoN200 and nogo-P300 components in both groups. There were no group differences in the grand average of N200 amplitudes at the $\mathrm{Fz}, \mathrm{Cz}$, and $\mathrm{Pz}$ electrodes across the nogo stimuli. There was significant N200 latency at the Fz and Cz electrodes across nogo stimuli (Table 2).

The latency of the N200 component in children was significantly longer than that in adolescents at $\mathrm{Fz}$ (mean $=281.00, \mathrm{SD}=$ 28.96; mean $=243.46, \mathrm{SD}=38.01$, respectively; $\mathrm{p}<0.001$ ) and $\mathrm{Cz}$ electrodes (mean=276.32, $\mathrm{SD}=29.01$; mean $=247.17, \mathrm{SD}=24.55$, respectively; $\mathrm{p}<0.001$ ). Further, the amplitude of the P300 component in children was also considerably lower than that in adolescents at $\mathrm{Fz}$ (mean=-1.35, $\mathrm{SD}=3.48$; mean=1.29, $\mathrm{SD}=4.3$, respectively; $\mathrm{p}<0.05$ ) (Table 2 ). There were no group differences in the grand average of $\mathrm{P} 300$ latency at the $\mathrm{Fz}, \mathrm{Cz}$, and $\mathrm{Pz}$ electrodes across nogo stimuli.

\section{Correlation analysis}

We calculated Spearman's correlation coefficients (with Bonferroni-adjusted p-values) for the amplitude and latency of N200 and P300 components, as well as age (Table 3, Figure 2). There were negative correlations between age and N200 latency at Fz ( $\rho=-0.46$, Bonferroni-corrected $\mathrm{p}=0.01)$ and $\mathrm{Cz}(\rho=-0.60$, Bonferroni-corrected $\mathrm{p}=0.01)$. Although the Bonferroni-corrected p-value was not statistically significant, N200 latency (Table 3) showed a negative correlation with age at $\mathrm{Pz}(\rho=-0.35, \mathrm{p}=0.10)$. Moreover, P300 amplitude (Table 3) showed a positive correlation with age at $\mathrm{Fz}(\rho=0.32, \mathrm{p}=0.19)$ and $\mathrm{Cz}(\rho=0.30, \mathrm{p}=0.26)$.

\section{$\mathrm{N} 200$ latency at $\mathrm{Fz}$ and $\mathrm{Cz}$ in nogo condition}

With a 1-year increase in age, the nogo-N200 latency at Fz and $\mathrm{Cz}$ significantly decreased by $6.08 \mathrm{~ms}$ and $4.88 \mathrm{~ms}$, respectively $(\mathrm{B}=-6.08, \mathrm{p}<0.001$ and $\mathrm{B}=-4.88, \mathrm{p}<0.001$; respectively), which was indicated in the multivariable linear regression with adjustment of sex and dominant hand (Table 4).

\section{DISCUSSION}

We assessed the associations and regressions of auditory nogo-N200 and nogo-P300 components in children and adolescents with ADHD. This study has several key findings. First, the auditory nogo-N200 latency in children was significantly longer than in adolescents at Fz and $\mathrm{Cz}$. Second, the auditory nogo-P300 amplitude in children was significantly lower than in adolescents at Fz. Third, multivariable linear regression with adjustment for sex and the dominant hand showed that older children and adolescents with ADHD had shorter auditory nogo-N200 latency at Fz and Cz.

We found that N200 latency at the Fz and Cz electrodes was significantly greater in children than that in adolescents; these 
results are similar to those of previous studies; ${ }^{14,18}$ however, these previous studies assessed healthy controls but not patients with ADHD. Enoki et al. ${ }^{18}$ demonstrated that N200 latency decreased with age during childhood and gradually increased during adulthood. Moreover, consistent with our findings, Van der Stelt et al. ${ }^{36}$ reported a negative correlation of N200 and P300 laten- cies with age during the transition from childhood to adulthood. It has been proposed that N200 latency decreases due to brain maturation from childhood to adulthood. ${ }^{36}$ Our results are limited to $\mathrm{N} 200$ latency changes at $\mathrm{Fz}$ and $\mathrm{Cz}$; contrastingly, van der Stelt et al..$^{36}$ showed shorter N200 and P300 latencies at all electrodes. The nogo-N200 component could reflect an
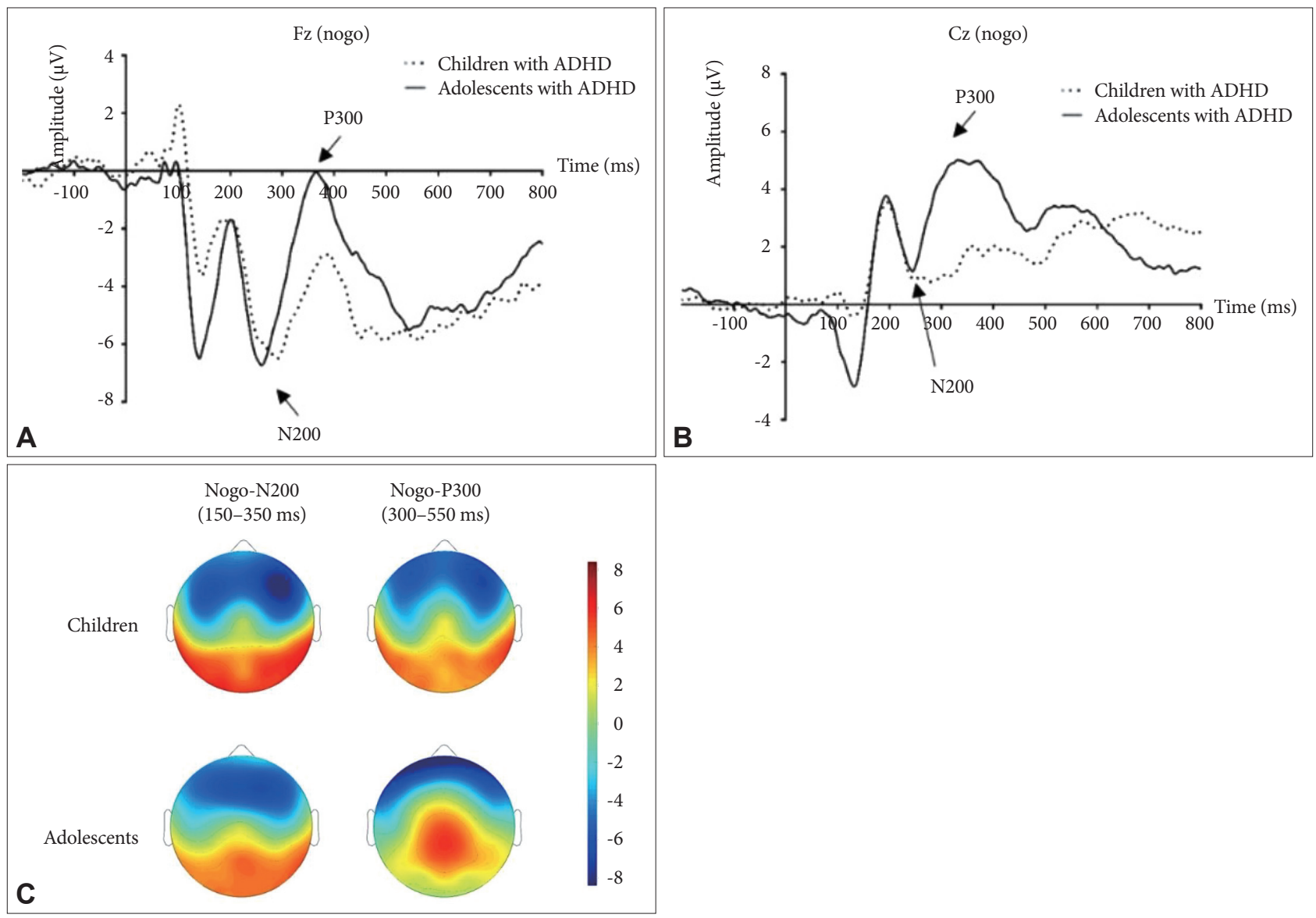

Figure 1. A: Grand averages of auditory evoked potentials at the Fz electrode in children and adolescents with ADHD. B: Grand averages of auditory evoked potentials at the Cz electrode in both groups. C: Scalp topographies of nogo- N200 and P300 components between the two groups.

Table 2. Grand averages of nogo-N200 latencies and nogo-P300 amplitudes at Fz, Cz, and Pz electrodes in children and adolescents with ADHD

\begin{tabular}{|c|c|c|c|c|c|}
\hline & \multicolumn{2}{|c|}{ Children $(\mathrm{N}=22)$} & \multicolumn{2}{|c|}{ Adolescents (N=24) } & \multirow{2}{*}{$\mathrm{p}$} \\
\hline & Mean & $\mathrm{SD}$ & Mean & $\mathrm{SD}$ & \\
\hline \multicolumn{6}{|c|}{ Nogo-N200 latency (ms) } \\
\hline $\mathrm{Fz}$ & 281.00 & 28.96 & 243.46 & 38.01 & $<0.001^{* * *}$ \\
\hline $\mathrm{Cz}$ & 276.32 & 29.01 & 247.17 & 24.55 & $<0.001^{* * *}$ \\
\hline $\mathrm{Pz}$ & 254.59 & 56.79 & 241.21 & 42.06 & 0.37 \\
\hline \multicolumn{6}{|c|}{ Nogo-P300 amplitude $(\mu \mathrm{V})$} \\
\hline $\mathrm{Fz}$ & -1.35 & 3.48 & 1.29 & 4.3 & $0.03^{*}$ \\
\hline $\mathrm{Cz}$ & 4.17 & 4.76 & 6.64 & 4.57 & 0.08 \\
\hline $\mathrm{Pz}$ & 5.86 & 3.78 & 6.95 & 5.29 & 0.43 \\
\hline
\end{tabular}

p-values were calculated using the Mann-Whitney $\mathrm{U}$ test. ${ }^{*} \mathrm{p}<0.05,{ }^{* * *} \mathrm{p}<0.001$. N200: negative 200, P300: positive 300, SD: standard deviation, Fz: frontal electrode, Cz: central electrode, Pz: parietal electrode 
Table 3. Correlations of age with N200 and P300 components in children and adolescents with ADHD

\begin{tabular}{ccc}
\hline & \multicolumn{2}{c}{ Spearman's correlation } \\
\cline { 2 - 3 } & \multicolumn{2}{c}{ Children and adolescents N=46 } \\
\hline Nogo-N200 latency (ms) & -0.46 & $\mathrm{p}$ \\
$\mathrm{Fz}$ & -0.60 & $0.01^{*}$ \\
$\mathrm{Cz}$ & -0.35 & $0.01^{*}$ \\
$\mathrm{Pz}$ & & 0.10 \\
$\mathrm{Nogo}-\mathrm{P} 300$ amplitude $(\mu \mathrm{V})$ & 0.32 & $\mathrm{p}$ \\
$\mathrm{Fz}$ & 0.30 & 0.19 \\
$\mathrm{Cz}$ & 0.26 \\
$\mathrm{Pz}$ & 0.04 & 1.00 \\
\hline
\end{tabular}

p-values were calculated for Spearman's correlations with Bonferroni correction. ${ }^{*} \mathrm{p}<0.05$. $\rho$ : Spearman's correlation coefficient, N200: negative 200, P300: positive 300, SD: standard deviation, Fz: frontal electrode, Cz: central electrode, Pz: parietal electrode early mechanism of inhibitory control. ${ }^{25}$ Difficulty in discrimination ${ }^{37}$ has been demonstrated to be abnormally high in children with ADHD relative to that in healthy controls, especially with respect to nogo-N200 in the prefrontal area. ${ }^{5,24,38,39} \mathrm{fMRI}$ studies using stop signal tasks ${ }^{5,40}$ reported that the right middle/ inferior frontal gyrus is critically involved in inhibitory control in healthy individuals. The inconsistency between our findings and related previous studies could be attributed to differences in the participants' ages and the presence/absence of ADHD.

Our results indicate that the auditory nogo-P300 amplitude in children was significantly lower than in adolescents at Fz. The P300 component has been shown to reflect important cognitive domains in $\mathrm{ADHD}$, including executive and attentional functions such as updating of working memory, event categorization, and attentional resource allocation (attentional reorientation). ${ }^{41,42}$ In individuals with ADHD, lower P300 amplitude

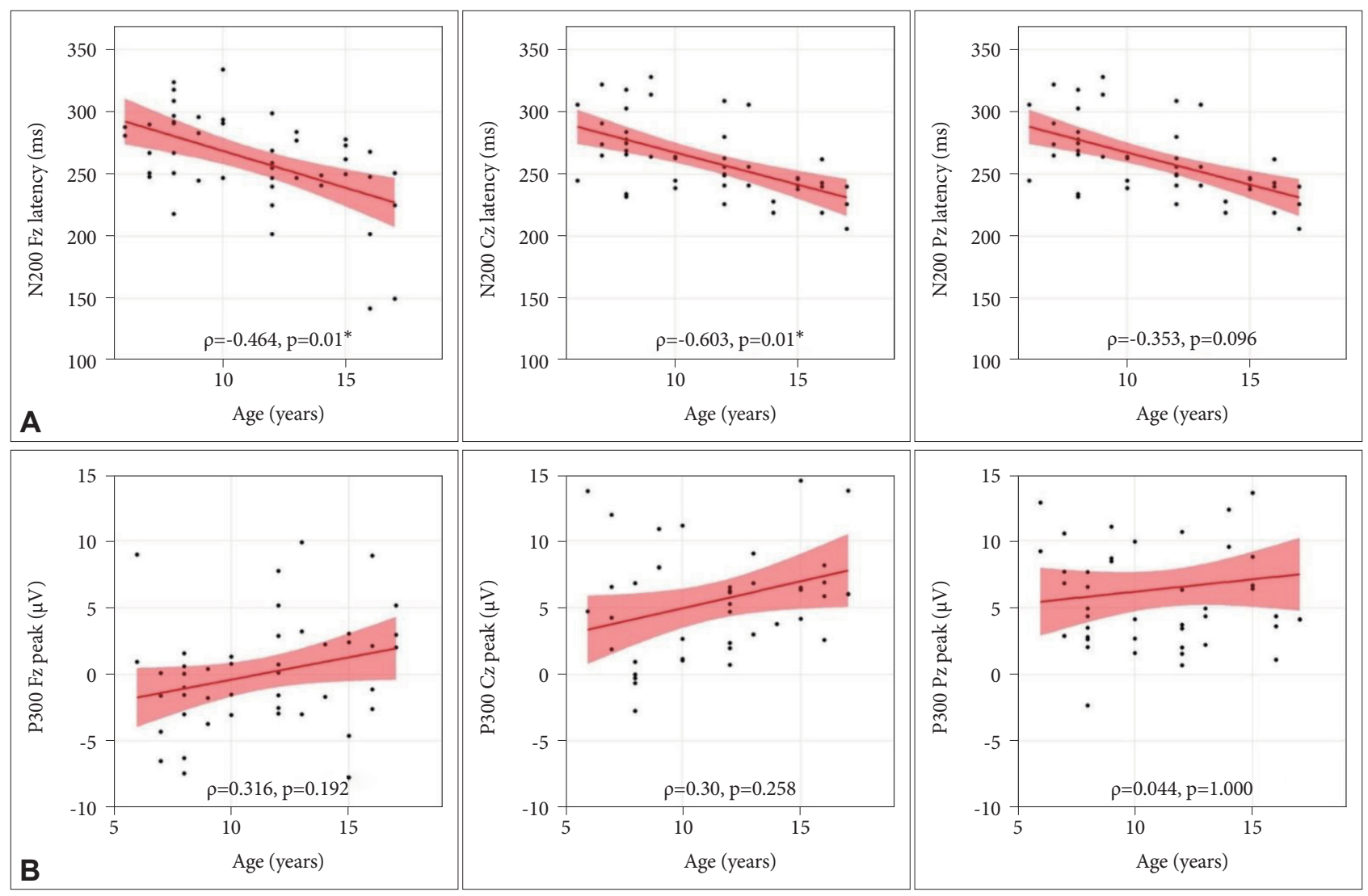

Figure 2. Correlations between event-related potentials and age in children and adolescents with $A D H D$. (A) nogo-N200 latency at Fz, $\mathrm{Cz}$, and Pz. (B) nogo-P300 amplitude at Fz, Cz, and Pz. p-values were calculated by Spearman's correlation. *Bonferroni adjusted p-values<0.05. p: Spearman's correlation coefficient, N200: negative 200, SD: standard deviation, Fz: frontal electrode, Cz: central electrode, Pz: parietal electrode.

Table 4. Multivariable regression analysis of the association between electrode location and nogo-N200 latency

\begin{tabular}{cccccc}
\hline \multirow{2}{*}{ Variable } & \multicolumn{2}{c}{ Model I (Fz) } & & \multicolumn{2}{c}{ Model II (Cz) } \\
\cline { 2 - 3 } \cline { 5 - 6 } & $\mathrm{B}(95 \% \mathrm{CI})$ & $\mathrm{p}$-value & $\mathrm{B}(95 \% \mathrm{CI})$ & $\mathrm{p}$-value \\
\hline Age of children and adolescents & $-6.08(-9.24,-2.92)$ & $<0.001^{* * *}$ & & $-4.88(-7.16,-2.61)$ & $<0.001^{* * *}$ \\
\hline
\end{tabular}

Model I: nogo-N200 latency at the frontal electrode (Fz) adjusted for sex and dominant hand, Model II: nogo-N200 latency at the central electrode $(\mathrm{Cz})$ adjusted for sex and dominant hand. ${ }^{* * *} \mathrm{p}<0.001$. B: regression coefficient, CI: confidence interval 
is reported to represent deficits in process task-relevant or salient information, context updating, and selective attention. ${ }^{43}$ ADHD develops between childhood and adolescence, with symptoms improving with brain maturation, ${ }^{44}$ which could be reflected in P300. The ATA index, K-ARS-IV, and CBCL scores were lower in adolescents than in children. However, these differences were not statistically significant. Therefore, age-related changes in P300 amplitude could be attributed to the maturation of executive and attentional functions in the brains of children and adolescents with ADHD.

Finally, multivariable linear regression (adjusted for sex and the dominant hand) revealed a negative correlation of age with the latency of auditory nogo N200 at the Fz and Cz. The N200 component is related to an early mechanism of inhibitory control, ${ }^{20,25,39}$ which matches the stimuli to an internally generated contextual template. ${ }^{45}$ Moreover, it is connected with the initial stimulus categorization in the selective attention stream ${ }^{46} \mathrm{We}$ evaluated the N200 components when response inhibition was not performed for a stop signal task during the go-nogo paradigms. Kok et al. ${ }^{47}$ reported that N200 components evaluated using the go-nogo paradigm are less sensitive to the stop signal than P300 components. However, they can better express changes caused by an unsuccessful stop in the fronto-central area than the P300 components. ${ }^{48,49}$ Therefore, the results of Kok et al. ${ }^{47}$ support our findings and indicate that the N200 component could be a useful tool for evaluating response inhibition in children with ADHD. We confirmed a decrease in the N200 latency by $6.08 \mathrm{~ms}$ at $\mathrm{Fz}$ and $4.88 \mathrm{~ms}$ at $\mathrm{Cz}$ with increasing age. According to previous fMRI studies, ${ }^{3,6,9}$ the velocity of prefrontal cortex thinning was delayed in children with ADHD compared to that in healthy controls. However, it was difficult to confirm the association between ADHD and a delay in brain maturation as we did not include healthy controls. Further studies should be conducted with ERPs from larger samples including a healthy-control group to confirm these findings.

\section{Limitations}

There are several limitations to consider when interpreting the results of this study. First, as this study employed a cross-sectional design, it is difficult to eliminate inter-individual changes. A longitudinal study is necessary to accurately analyze the developmental path. Second, the study did not involve a comparison of individuals with and without ADHD. To clarify developmental differences between typically developing children and adolescents and those with ADHD, it is necessary to compare the latter with healthy controls. Third, it is difficult to generalize the results of this study as it evaluated children and adolescent patients who visited a single university hospital. Therefore, there is a need for a multicenter study with a long-term follow-up period. Fourth, the sample size was too small to iden-

tify sex-based variations in N200 and P300. There are sex differences in neurotransmitter activity and brain structures, which are known to affect overall ERP profiles. ${ }^{15,35}$ While the linear regression analysis was adjusted for sex and dominant hand, future research is needed to analyze sex differences in detail.

\section{Conclusion}

Despite the aforementioned limitations, this study provided novel evidence that changes in frontal N200 latency occurred with age in children with ADHD. Although this study did not directly compare the individuals with ADHD with healthy controls, inhibitory control changes in children with ADHD probably follow a developmental trajectory. Future large-scale, longitudinal studies on children and adolescents with ADHD, as well as healthy controls, are necessary to accurately identify the neural developmental trajectory in children and adolescents with ADHD.

\section{Acknowledgments}

This work was supported by a National Research Foundation of Korea (NRF) grant funded by the Korea government (MSIT) (No. 2017R1C1B5074462) and the Soonchunhyang University Research Fund. The funders had no role in study design, data collection and analysis, the decision to publish, or preparation of the manuscript.

\section{Conflicts of Interest}

The authors have no potential conflicts of interest to disclose.

\section{Author Contributions}

Conceptualization: Yeon Jung Lee. Data curation: Yeon Jung Lee. Formal analysis: Yeon Jung Lee. Funding acquisition: Yeon Jung Lee. Investigation: Mi Young Jeong, Seoyoung Park. Methodology: Yeon Jung Lee, Jung Ho Kim. Project administration: Yeon Jung Lee. Resources: Yeon Jung Lee. Software: Yeon Jung Lee, Junh Ho Kim. Supervision: Sung-Il Woo, Ji-Sun Kim. Validation: Ji-Sun Kim, Yeon Jung Lee. Visualization: Yeon Jung Lee. Writing_original draft: Yeon Jung Lee. Writing_review \& Editing: Yeon Jung Lee, Sung-Il Woo, Ji-Sun Kim.

\section{ORCID iDs}

Yeon Jung Lee Mi Young Jeong Seoyoung Park Jung Ho Kim Ji-Sun Kim

Sung-Il Woo

$$
\begin{aligned}
& \text { https://orcid.org/0000-0001-8953-5893 } \\
& \text { https://orcid.org/0000-0002-2409-8060 } \\
& \text { https://orcid.org/0000-0002-5033-8689 } \\
& \text { https://orcid.org/0000-0003-2763-7186 } \\
& \text { https://orcid.org/0000-0003-2472-4591 } \\
& \text { https://orcid.org/0000-0002-1661-095X }
\end{aligned}
$$

\section{REFERENCES}

1. Polanczyk GV, Willcutt EG, Salum GA, Kieling C, Rohde LA. ADHD prevalence estimates across three decades: an updated systematic review and meta-regression analysis. Int J Epidemiol 2014;43:434-442.

2. Thomas R, Sanders S, Doust J, Beller E, Glasziou P. Prevalence of attention-deficit/hyperactivity disorder: a systematic review and meta-analysis. Pediatrics 2015;135:e994-e1001.

3. American Psychiatric Association. Diagnostic and Statistical Manual of Mental Disorders (DSM- $\left.5^{\circledR}\right)$. Washington, DC: American Psychiatric Pub; 2013.

4. Barkley RA, Anastopoulos AD, Guevremont DC, Fletcher KE. Adolescents with ADHD: patterns of behavioral adjustment, academic functioning, and treatment utilization. J Am Acad Child Adolesc Psychia- 
try 1991;30:752-761.

5. Rubia K. Neuro-anatomic evidence for the maturational delay hypothesis of ADHD. Proc Natl Acad Sci USA 2007;104:19663-19664.

6. Shaw P, Eckstrand K, Sharp W, Blumenthal J, Lerch J, Greenstein D, et al. Attention-deficit/hyperactivity disorder is characterized by a delay in cortical maturation. Proc Natl Acad Sci USA 2007;104:9649-19654.

7. Dickstein SG, Bannon K, Xavier Castellanos F, Milham MP. The neural correlates of attention deficit hyperactivity disorder: an ALE metaanalysis. J Child Psychol Psychiatry 2006;47:1051-1062.

8. Chabot RJ, Serfontein G. Quantitative electroencephalographic profiles of children with attention deficit disorder. Biol Psychiatry 1996;40:951-963.

9. Shaw P, Gilliam M, Liverpool M, Weddle C, Malek M, Sharp W, et al. Cortical development in typically developing children with symptoms of hyperactivity and impulsivity: support for a dimensional view of attention deficit hyperactivity disorder. Am J Psychiatry 2011;168:143-151.

10. Courchesne E. Chronology of Postnatal Human Brain Development: Event-Related Potential, Positron Emission Tomography, Myelinogenesis, and Synaptogenesis Studies. In: Rohrbaugh JWR, Parasuraman R, Editors. Event-Related Brain Potentials: Basic Issues and Applications. New York: Oxford University Press, 1990, p.210-241.

11. Steinschneider M, Kurtzberg D, Vaughan JHG. Event-Related Potentials in Developmental Neuropsychology. In: Rapin I, Segalowitz SJ, Editors. Handbook of Neuropsychology: Amsterdam: Elsevier, 1992, p.239-299.

12. Campbell IG, Grimm KJ, De Bie E, Feinberg I. Sex, puberty, and the timing of sleep EEG measured adolescent brain maturation. Proc Natl Acad Sci USA 2012;109:5740-5743.

13. Patel SH, Azzam PN. Characterization of N200 and P300: selected studies of the event-related potential. Int J Med Sci 2005;2:147-154.

14. Enoki H. P300 of auditory event-related potentials: the effects of development and aging in humans. Jpn JEEG 1990;18:60-67.

15. Hirayasu Y, Samura M, Ohta H, Ogura C. Sex effects on rate of change of P300 latency with age. Clin Neurophysiol 2000;111:187-194.

16. Polich J. Meta-analysis of P300 normative aging studies. Psychophysiology 1996;33:334-353.

17. Polich J. P300 in the Evaluation of Aging and Dementia. In: Brunia CHM, Mulder G, Verbaten MN, Editors. Event-Related Brain Research. (Electroencephalogr Clin Neurophysiol Suppl 42). Amsterdam: Elsevier, 1991, p.304-323.

18. Enoki H, Sanada S, Yoshinaga H, Oka E, Ohtahara S. The effects of age on the N200 component of the auditory event-related potentials. Psychophysiology 1993;1:161-167.

19. Nichols SL, Waschbusch DA. Development H. A review of the validity of laboratory cognitive tasks used to assess symptoms of ADHD. Child Psychiatry Hum Dev 2004;34:297-315.

20. Falkenstein M, Hoormann J, Hohnsbein J. Inhibition-related ERP components: Variation with modality, age, and time-on-task. J Psychophysiol 2002;16:167-175.

21. Smith JL, Johnstone SJ, Barry RJ. Inhibitory processing during the Go/ NoGo task: an ERP analysis of children with attention-deficit/hyperactivity disorder. Clin Neurolphysiol 2004;115:1320-1331.

22. Fallgatter AJ, Ehlis AC, Seifert J, Strik WK, Scheuerpflug P, Zillessen $\mathrm{KE}$, et al. Altered response control and anterior cingulate function in attention-deficit/hyperactivity disorder boys. Clin Neurolphysiol 2004; 115:973-981.

23. Nieuwenhuis S, Yeung N, Van Den Wildenberg W, Ridderinkhof KR. Electrophysiological correlates of anterior cingulate function in a go/ no-go task: effects of response conflict and trial type frequency. Cogn Affect Behav Neurosci 2003;3:17-26.

24. Albrecht B, Banaschewski T, Brandeis D, Heinrich H, Rothenberger A. Response inhibition deficits in externalizing child psychiatric disorders: an ERP-study with the Stop-task. Behav Brain Funct 2005;1:22.

25. Jodo E, Kayama Y. Relation of a negative ERP component to response inhibition in a Go/No-go task. Electroencephalogr Clin Neurophysiol 1992;82:477-482.

26. Lopez J, Lopez V, Rojas D, Carrasco X, Rothhammer P, García R, et al. Effect of psychostimulants on distinct attentional parameters in attentional deficit/hyperactivity disorder. Biol Res 2004;37:461-468.
27. Seifert J, Scheuerpflug P, Zillessen KE, Fallgatter A, Warnke A. Electrophysiological investigation of the effectiveness of methylphenidate in children with and without ADHD. J Neural Transm 2003;110:821-829.

28. DuPaul GJ, Power TJ, Anastopoulos AD, Reid R. ADHD Rating ScaleIV: Checklists, Norms, and Clinical Interpretation. New York, NY: Guilford Press; 1998.

29. Jang SJ, Suh DS, Byun HJ. Normative study of the K-ARS (Korean ADHD Rating Scale) for parents. Korean J Child Adolesc Psychiatry 2007;18: 38-48.

30. Cho SZ, Chun SY, Hong KE, Shin MS. Psychiatry A. A study of the development and standardization of ADHD diagnostic system. Korean J Child Adolesc Psychiatry 2000;11:91-99.

31. Achenbach T, Achenbach TM, Achebach T. Integrative Guide for the 1991 CBCL/4-18, YSR, and TRF Profiles. Burlington: Department of Psychiatry, University of Vermont; 1991.

32. Oh KJ, Lee H. Development of Korean child behavior checklist: a preliminary study. J Korean Neuropsychiatr Assoc 1990;29:452-462.

33. Semlitsch HV, Anderer P, Schuster P, Presslich O. A solution for reliable and valid reduction of ocular artifacts, applied to the P300 ERP. Psychophysiology 1986;23:695-703.

34. Rose K, Van den Anker JN. Guide to Paediatric Clinical Research. In: Rose K, Van den Anker JN, Editors. Clinical Investigation of Medicinal Products In the Paediatric Population. Basel: Karger, 2007, p.33-37.

35. Polich J, Hoffman LD. P300 and handedness: on the possible contribution of corpus callosal size to ERPs. Psychophysiology 1998;35:497-507.

36. Van der Stelt O, Kok A, Smulders FT, Snel J, Gunning WB. Cerebral event-related potentials associated with selective attention to color: developmental changes from childhood to adulthood. Psychophysiology 1998;35:227-239.

37. Porjesz B, Begleiter H. The N2 component of the event-related potential in schizophrenic patients. Clin Neurophysiol 1987;66:369-375.

38. Liotti M, Pliszka SR, Perez III R, Luus B, Glahn D, Semrud-Clikeman M. Electrophysiological correlates of response inhibition in children and adolescents with ADHD: influence of gender, age, and previous treatment history. Psychophysiology 2007;44:936-948.

39. Liotti M, Pliszka SR, Higgins K, Perez III R, Semrud-Clikeman M, Evidence for specificity of ERP abnormalities during response inhibition in ADHD children: a comparison with reading disorder children without ADHD. Brain Cogn 2010;72:228-237.

40. Konishi S, Nakajima K, Uchida I, Kikyo H, Kameyama M, Miyashita Y. Common inhibitory mechanism in human inferior prefrontal cortex revealed by event-related functional MRI. Brain 1999;122:981-991.

41. Donchin E, Coles MG. Is the P300 component a manifestation of context updating? Behav Brain Sci 1988;11:357-374.

42. Polich J. Updating P300: an integrative theory of P3a and P3b. Clin Neurophysiol 2007;118:2128-2148.

43. Satterfield JH, Schell AM, Nicholas TW, Satterfield BT, Freese TE. Ontogeny of selective attention effects on event-related potentials in attention-deficit hyperactivity disorder and normal boys. Biol Psychiatry 1990; 28:879-903.

44. Mannuzza S, Klein RG, Bonagura N, Malloy P, Giampino TL, Addalli KA. Hyperactive boys almost grown up: V. Replication of psychiatric status. Arch Gen Psychiatry 1991;48:77-83.

45. Gehring WJ, Gratton G, Coles MG, Donchin E. Probability effects on stimulus evaluation and response processes. J Exp Psychol Hum Percept Perform 1992;18:198-216.

46. Calhoun VD, Wu L, Kiehl KA, Eichele T, Pearlson GD. Aberrant processing of deviant stimuli in schizophrenia revealed by fusion of fMRI and EEG data. Acta Neuropsychiatr 2010;22:127-138.

47. Kok A, Ramautar JR, De Ruiter MB, Band GP, Ridderinkhof KR. ERP components associated with successful and unsuccessful stopping in a stop-signal task. Psychophysiology 2004;41:9-20.

48. Enriquez-Geppert S, Konrad C, Pantev C, Huster RJ. Conflict and inhibition differentially affect the N200/P300 complex in a combined go/ nogo and stop-signal task. Neuroimage 2010;51:877-887.

49. Ramautar JR, Kok A, Ridderinkhof KR. Effects of stop-signal probability in the stop-signal paradigm: the N2/P3 complex further validated. Brain Cogn 2004;56:234-252. 